\title{
The Covariance Structure of Residual Effects in a Reduced Animal Model for Marker-Assisted Selection
}

\author{
Seiko SAITO and Hiroaki IWAISAKI* \\ Graduate School of Science and Technology, Niigata University, \\ Niigata-shi $950-21$ \\ * Faculty of Agriculture, Niigata University, Niigata-shi 950-21
}

(Received August. 2, 1996)

\begin{abstract}
For a reduced animal model (RAM) for marker-assisted selection using best linear unbiased prediction, the appropriate structure of covariance matrix of the segregation residual effects is derived for the situation where paternal or matemal origin of marker alleles can not be determined. A RAM approach is then described, in which the covariance structure is taken into account. Formulae for backsolving for non-parent animals are presented. A small numerical example is also given to illustrate the current RAM approach.
\end{abstract}

Anim. Sci. Technol. (Jpn.) 68 (1): 1-6,1997

Key words : Marker-assisted selection, Best linear unbiased prediction, Reduced animal model, Covariance, Segregation residual

A large number of genetic polymorphisms such as restriction fragment length polymorphisms ${ }^{1)}$, variable number of tandem repeats $^{6,9)}$ and random amplified polymorphic DNA $^{17)}$ are now being detected by molecular techniques. The genetic differences identified at the DNA level are referred to as genetic markers. The use in selection criteria of information on marker loci which are linked to quantitative trait loci (QTLs), that is markerassisted selection (MAS), is expected to be useful for accelerating genetic progress through increased accuracy of selection, reduced generation interval and increased selection differential $1^{7,8,12,13)}$.

In the field of animal breeding, best linear unbiased prediction (BLUP) $)^{5)}$ is used for predicting breeding values from data affected by non-genetic nuisance factors, non-random mating, selection and so on. Fernando and Grossman ${ }^{3)}$ showed how marker information could be utilized in the animal model (AM)BLUP method. The AM approach permits simultaneous evaluation of fixed effects, effects of alleles at a QTL linked to the marker locus (MQTL) and effects of alleles at the remaining QTLs. As size of data sets becomes large, however, the computational burden in the AM method would dramatically increase. Therefore, Cantet and $\mathrm{Smith}^{2)}$ presented the reduced animal model (RAM) version of Fernando and Grossman's AM approach ${ }^{3)}$, by which the total number of equations to be solved could be considerably reduced. However, when there are animals whose paternal or maternal origin of marker alleles is uncertain in the relevant pedigree, the covariance structure of residual effects in Cantet and Smith's RAM ${ }^{2)}$ is no longer true.

The main purpose of this paper is to appropriately define the covariance matrix of segregation residuals in the RAM for the situa- 
tion where parental origin of marker alleles can not be determined. The RAM approach in which the covariance matrix has been incorporated is also presented. The results for the covariance structure of the residuals obtained in this stucly have been used in the RAM procedures for MAS developed by Saito and Iwaisaki ${ }^{10,11)}$.

\section{Theory}

\section{Fernando and Grossman's $A M$}

For simplicity, consider a single polymorphic marker locus. Then the breeding value $\left(a_{j}\right)$ of animal $i$ is written as the sum of additive genetic effects for alleles at the QTLs unlinked to the marker locus $\left(u_{i}\right)$ and additive effects of the MQTL alleles $\left(v_{i}^{1}\right.$ and $\left.v_{i}^{2}\right)$, that is $a_{i}=u_{i}+v_{i}^{1}+v_{i}^{2}$. Then the $\mathrm{AM}^{3)}$ is written, as follows

$$
\begin{aligned}
\mathbf{y} & =\mathbf{X} \boldsymbol{\beta}+\mathbf{Z} \mathbf{a}+\mathbf{e} \\
& =\mathbf{X} \boldsymbol{\beta}+\mathbf{Z} \mathbf{u}+\mathbf{Z P v}+\mathbf{e},
\end{aligned}
$$

where $\mathbf{y}$ is the $n \times 1$ vector of observations, $\beta$ is the $f \times 1$ vector of fixed effects, a is the $n \times 1$ vector of the total additive genetic merits, $\mathbf{u}$ is the $q \times 1$ vector of additive genetic effects due to QTLs not linked to the marker locus, $\mathbf{v}$ is the $2 q \times 1$ vector of additive effects of the MQTL alleles, $\mathrm{e}$ is the $n \times 1$ vector of residual effects, and $\mathbf{X}, \boldsymbol{Z}$ and $\boldsymbol{P}$ are $n \times f, n \times q$ and $q \times 2 q$ known incidence matrices, respectively. The expectation and dispersion matrices for the random effects, $\mathbf{u}, \mathbf{v}$ and $\mathbf{e}$, are assumed as

$$
\mathrm{E}\left(\begin{array}{l}
\mathbf{u} \\
\mathbf{v} \\
\mathbf{e}
\end{array}\right)=\left(\begin{array}{l}
0 \\
0 \\
0
\end{array}\right) \text { and } \operatorname{Var}\left(\begin{array}{l}
\mathbf{u} \\
\mathbf{v} \\
\mathbf{e}
\end{array}\right)=\left(\begin{array}{ccc}
\mathbf{A}_{\mathrm{u}} \boldsymbol{\sigma}_{u}^{2} & \mathbf{0} & \mathbf{0} \\
0 & \mathbf{A}_{\mathbf{v}} \boldsymbol{\sigma}_{v}^{2} & \mathbf{0} \\
0 & \mathbf{0} & \mathbf{I} \boldsymbol{\sigma}_{e}^{2}
\end{array}\right)
$$

respectively, where $A_{u}$ is the numerator relationship matrix for the QTLs not linked to the marker locus, $\mathbf{A}_{\mathbf{v}}$ is the gametic relationship matrix for the MQTL, I is an identity matrix, and $\sigma_{u}^{2}, \sigma_{v}^{2}$ and $\sigma_{e}^{2}$ are the variance components for $\mathbf{u}, \mathbf{v}$ and $\mathbf{e}$, respectively.

For MAS, mixed model methodology used for predicting breeding values requires the inverses of $\mathbf{A}_{\mathbf{u}}$ and $\mathbf{A}_{\mathbf{v}}$. Fernando and Grossman $^{3)}$ presented an algorithm to directly construct the inverse of $\mathbf{A}_{v} \boldsymbol{\sigma}_{v}^{2}$. In the algorithm, it is assumed that the covariance matrix of residual effects for the MQTL is diagonal. However, if paternal or maternal origin of marker alleles can not be determined, it is not true.

\section{Cantet and Smith's RAM}

Cantet and $S$ mith ${ }^{2)}$ described the RAM version of Fernando and Grossman's $\mathrm{AM}^{33}$. If animals can be partitioned into parents and non-parents, eq. (1) can be arranged as

$$
\begin{aligned}
\left(\begin{array}{l}
\mathbf{y}_{p} \\
\mathbf{y}_{o}
\end{array}\right)= & \left(\begin{array}{l}
\mathbf{X}_{p} \\
\mathbf{X}_{o}
\end{array}\right) \beta+\left(\begin{array}{cc}
\mathrm{Z}_{p} & 0 \\
0 & \mathbf{Z}_{o}
\end{array}\right)\left(\begin{array}{l}
\mathbf{u}_{\rho} \\
\mathbf{u}_{o}
\end{array}\right) \\
& +\left(\begin{array}{cc}
\mathbf{Z}_{p} \mathbf{P}_{p} & 0 \\
0 & \mathbf{Z}_{o} \mathbf{P}_{o}
\end{array}\right)\left(\begin{array}{l}
\mathbf{v}_{p} \\
\mathbf{v}_{o}
\end{array}\right)+\left(\begin{array}{l}
\mathbf{e}_{p} \\
\mathbf{e}_{o}
\end{array}\right),
\end{aligned}
$$

where the subscripts $p$ and $o$ refer to animals with progeny and without progeny, respectively. For the RAM, $\mathbf{u}_{o}$ and $\mathbf{v}_{o}$ are expressed as a linear function of $\mathbf{u}_{p}$ and $\mathbf{v}_{p}$, respectively, as follows

$$
\mathbf{u}_{o}=\mathbf{T} \mathbf{u}_{p}+\mathbf{m}
$$

and

$$
\mathrm{v}_{o}=\mathbf{B} \mathrm{v}_{p}+\varepsilon
$$

where $\mathbf{T}$ is a matrix relating $\mathbf{u}_{o}$ to $\mathbf{u}_{p}$ and has zeros except for .5 in the column pertaining to a known parent, $\mathbf{m}$ is a vector of the Mendelian sampling effects, $\mathbf{B}$ is a matrix relating $\mathbf{v}_{\boldsymbol{o}}$ to $\mathbf{v}_{\boldsymbol{p}}$ and contains two non-zero elements in each row if the parental origins of marker alleles are known, as discussed by Fernando and Grossman ${ }^{3)}$, and $\varepsilon$ is a vector of segregation residuals. The Mendelian sampling effects $\mathbf{m}$ follow $E(\mathbf{m})=\mathbf{0}$ and $\operatorname{Var}(\mathbf{m})=\mathbf{D} \boldsymbol{\sigma}_{u}^{2}$, where $\mathbf{D}$ is the diagonal matrix whose diagonal elements, $d_{i}$, equal .5-.25 $\left(F_{s}+F_{d}\right)$ with the inbreeding coefficients of the sire and the dam, $F_{s}$ and $F_{d}$. And also, the segregation residuals $\varepsilon$ have $\mathrm{E}(\varepsilon)$ $=\mathbf{0}$ and $\operatorname{Var}(\boldsymbol{\varepsilon})=\mathbf{G}_{\varepsilon} \boldsymbol{\sigma}_{v}^{2}$, where $\mathbf{G}_{\boldsymbol{\varepsilon}}$ is the diagonal matrix and contains the diagonal elements $\mathbf{G}_{\dot{\varepsilon}}$ $=2 r(1-r)\left(1-f_{s}\right)$ and $\mathbf{G}_{\varepsilon_{i}^{2}}=2 r(1-r)\left(\mathbf{1}-f_{d}\right)$. letting $r$ be recombination rate between the marker locus and MQTL and $f_{s}$ and $f_{d}$ be the inbreeding coefficients at the MQTL ${ }^{15)}$ of the 
sire and of the dam, respectively.

\section{The proposed covariance matrix}

Now, consider the situation where paternal or maternal origin of marker alleles can not be determined. The additive effects of the MQTL alleles of animal $i$ are

$$
v_{i}^{1}=b_{11}^{1} v_{s}^{1}+b_{i 2}^{1} v_{s}^{2}+b_{i 3}^{1} v_{d}^{1}+b_{i 1}^{1} v_{d}^{2}+\varepsilon_{i}^{1}
$$

and

$$
v_{i}^{2}=b_{i 1}^{2} v_{s}^{1}+b_{i 2}^{2} v_{s}^{2}+b_{i 3}^{2} v_{d}^{1}+b_{i 4}^{2} v_{d}^{2}+\varepsilon_{i,}^{2}
$$

where the coefficients $b_{i k}^{l}(l=1$ or 2 and $k=1,2,3$ or 4) are the conditional probabilities that the MQTL alleles of animal $i$ are copies of those of its parent, given the marker information (see eqs. [5], [6], [7] and [8] in Wang el al. ${ }^{15)}$ ). In matrix notation eqs. (5) and (6) are rewritten as

$$
\mathbf{v}_{o}=\mathbf{B}^{*} \mathbf{v}_{p}+\varepsilon \text {. }
$$

Then the covariance structure of the segregation residual effects becomes

$$
\begin{aligned}
& \left(\begin{array}{cc}
\operatorname{Var}\left(\varepsilon_{i}^{1}\right) & \operatorname{Cov}\left(\varepsilon_{i}^{1}, \varepsilon_{i}^{2}\right) \\
\operatorname{Cov}\left(\varepsilon_{i}^{1}, \varepsilon_{i}^{2}\right) & \operatorname{Var}\left(\varepsilon_{i}^{2}\right)
\end{array}\right) \\
& =\operatorname{Var}\left(\left[\begin{array}{ll}
v_{i}^{1} & \left.\left.v_{i}^{2}\right]^{\prime}\right)
\end{array}\right)-\mathbf{B}_{i}^{*} \operatorname{Var}\left(\left[\begin{array}{llll}
v_{s}^{1} & v_{s}^{2} & v_{d}^{1} & v_{d}^{2}
\end{array}\right]^{\prime}\right) \mathbf{B}_{i}^{*}\right. \\
& =\left[\left(\begin{array}{cc}
1 & f_{i} \\
f_{i} & 1
\end{array}\right)-\mathbf{B}_{i}^{*} \mathbf{A}_{\mathbf{v}_{p(i)}} \mathbf{B}_{i}^{* \prime}\right] \sigma_{v}^{2},
\end{aligned}
$$

where $f_{i}$ is the conditional inbreeding coefficient of animal $i$ for the MQTL, and $\mathbf{A}_{v_{p(i)}}$ is an appropriate submatrix of $\mathbf{A}_{\boldsymbol{v}}$ corresponding to the parental MQTL effects of animal $i$, and

$$
\mathbf{B}_{l}^{*}=\left[\begin{array}{llll}
b_{i 1}^{1} & b_{i 2}^{1} & b_{i 3}^{1} & b_{i 4}^{1} \\
b_{i 1}^{2} & b_{i 2}^{2} & b_{i 3}^{2} & b_{i 4}^{2}
\end{array}\right] \text {. }
$$

Hence, the covariance matrix of the segregation residual effects (denoted as $\mathrm{G}_{\varepsilon}^{*}$ ) is expressed as a block-diagonal matrix, which is different from that in Cantet and Smith's approach ${ }^{2}$.

The RAM approach with the covariance matrix proposed

Using eqs. (3) and (7) in eq. (2), a RAM model is given as

$$
\begin{aligned}
\left(\begin{array}{c}
\mathbf{y}_{p} \\
\mathbf{y}_{o}
\end{array}\right)= & \left(\begin{array}{l}
\mathbf{X}_{p} \\
\mathbf{X}_{o}
\end{array}\right) \boldsymbol{\beta}+\left(\begin{array}{c}
\mathbf{Z}_{p} \\
\mathbf{Z}_{o} \mathbf{T}
\end{array}\right) \mathbf{u}_{p}+\left(\begin{array}{c}
\mathbf{Z}_{p} \mathbf{P}_{p} \\
\mathbf{Z}_{o} \mathbf{P}_{o} \mathbf{B}^{*}
\end{array}\right) \mathbf{v}_{p} \\
& +\left(\begin{array}{c}
\mathbf{e}_{p} \\
\mathbf{Z}_{o} \mathbf{m}+\mathbf{Z}_{o} \mathbf{P}_{o} \varepsilon+\mathbf{e}_{o}
\end{array}\right) .
\end{aligned}
$$

With the appropriate matrices $Z_{\mathbf{t}}$ and $\mathbf{W}$, eq. (8) is further arranged as

$$
\mathbf{y}=\mathbf{X} \boldsymbol{\beta}+\mathbf{Z}_{\mathrm{t}} \mathbf{u}_{p}+\mathbf{W} \mathbf{v}_{p}+\phi .
$$

For the current RAM, assumptions on the expectation and dispersion parameters for the random effects are

$$
\mathrm{E}\left(\begin{array}{l}
\mathbf{u}_{p} \\
\mathbf{v}_{p} \\
\phi
\end{array}\right)=\left(\begin{array}{l}
0 \\
0 \\
0
\end{array}\right) \text { and } \operatorname{Var}\left(\begin{array}{l}
\mathbf{u}_{p} \\
\mathbf{v}_{p} \\
\phi
\end{array}\right)=\left(\begin{array}{ccc}
\mathbf{A}_{\mathbf{u}_{p}} \boldsymbol{\sigma}_{u}^{2} & 0 & 0 \\
0 & \mathbf{A}_{v_{p}} \sigma_{v}^{2} & 0 \\
0 & 0 & \mathbf{R}
\end{array}\right)
$$

where the matrices $\mathbf{A}_{u_{p}}$ and $\mathbf{A}_{v_{p}}$ are appropriate submatrices of $\mathbf{A}_{\mathrm{u}}$ and $\mathbf{A}_{\mathrm{v}}$, respectively, and $\mathbf{R}$ is defined as a diagonal matrix, as follows

$$
\left(\begin{array}{cc}
\mathrm{I}_{p} \sigma_{e}^{2} & 0 \\
0 & \mathrm{D} \sigma_{u}^{2}+\mathrm{P}_{o} \mathrm{G}_{\varepsilon}^{*} \mathrm{P}_{o}^{\prime} \sigma_{v}^{2}+\mathrm{I}_{o} \sigma_{e}^{2}
\end{array}\right) .
$$

Thus, the mixed model equations (MME) for the current RAM are given by

$$
\begin{gathered}
\left(\begin{array}{ccc}
\mathbf{X}^{\prime} \mathbf{R}^{-1} \mathbf{X} & \mathbf{X}^{\prime} \mathbf{R}^{-1} \mathbf{Z}_{\mathrm{t}} & \mathbf{X}^{\prime} \mathbf{R}^{-1} \mathbf{W} \\
\mathbf{Z}_{\mathrm{t}} \mathbf{R}^{-1} \mathbf{X} & \mathbf{Z}_{\mathrm{t}} \mathbf{R}^{-1} \mathbf{Z}_{\mathrm{t}}+\mathbf{A}_{\mathbf{u}_{p}}^{-1} \sigma_{u}^{-2} & \mathbf{Z}_{\mathbf{t}} \mathbf{R}^{-1} \mathbf{W} \\
\mathbf{W}^{\prime} \mathbf{R}^{-1} \mathbf{X} & \mathbf{W}^{\prime} \mathbf{R}^{-1} \mathbf{Z}_{\mathrm{t}} & \mathbf{W}^{\prime} \mathbf{R}^{-1} \mathbf{W}+\mathbf{A}_{\mathbf{v}_{p}}^{-1} \boldsymbol{\sigma}_{v}^{-2}
\end{array}\right) \\
\left(\begin{array}{c}
\beta^{\circ} \\
\hat{\mathbf{u}}_{p} \\
\hat{\mathbf{v}}_{p}
\end{array}\right)=\left(\begin{array}{l}
\mathbf{X}^{\prime} \mathbf{R}^{-1} \mathbf{y} \\
\mathbf{Z}_{\mathrm{t}}^{\prime} \mathbf{R}^{-1} \mathbf{y} \\
\mathbf{W}^{\prime} \mathbf{R}^{-1} \mathbf{y}
\end{array}\right) .
\end{gathered}
$$

\section{Backsolving for non-parents}

The additive genetic effects due to QTLS unlinked to the marker locus and the additive effects of the MQTL alleles for animals with no progeny can be predicted ${ }^{2}$ by the following equations

$$
\left(\begin{array}{c}
\hat{\mathbf{u}}_{o} \\
\hat{\mathbf{v}}_{o}
\end{array}\right)=\left(\begin{array}{cc}
\mathbf{T} & 0 \\
\mathbf{0} & \mathbf{B}^{*}
\end{array}\right)\left(\begin{array}{c}
\hat{\mathbf{u}}_{p} \\
\hat{\mathbf{v}}_{p}
\end{array}\right)+\left(\begin{array}{c}
\hat{\mathbf{m}} \\
\hat{\boldsymbol{\varepsilon}}
\end{array}\right),
$$

where

$$
\left(\begin{array}{c}
\hat{\mathbf{m}} \\
\hat{\varepsilon}
\end{array}\right)=\left(\begin{array}{cc}
\mathbf{I}_{o}+\mathbf{D}^{-1} \alpha_{u} & \mathbf{P}_{o} \\
\mathbf{P}_{o}^{\prime} & \mathbf{P}_{o}^{\prime} \mathrm{P}_{o}+\mathrm{G}_{\varepsilon}^{*-1} \alpha_{v}
\end{array}\right)^{-1}\left(\begin{array}{c}
\phi_{o} \\
\mathbf{P}_{o}^{\prime} \phi_{o}
\end{array}\right)
$$

with $\alpha_{u}=\sigma_{\varepsilon}^{2} / \sigma_{u s}^{2} \quad \alpha_{v}=\sigma_{\varepsilon}^{2} / \sigma_{v}^{2}$ and $\phi_{o}=\mathbf{y}_{o}-\mathbf{X}_{o} \beta^{\circ}-$ $\mathbf{T} \hat{\mathbf{u}}_{p}-\mathbf{P}_{o} \mathbf{B}^{*} \hat{\mathbf{v}}_{p}$. 


\section{Numerical example}

We use a small example including five animals, four parents and one non-parent, as given in Table 1. The recombination rate and the variance components are assumed as $r=1$, $\sigma_{u}^{2}=.3, \sigma_{\nu}^{2}=.05$ and $\sigma_{c}^{2}=.8$, respectively. We also assume

$$
\mathrm{X}=\left(\begin{array}{lllll}
1 & 1 & 1 & 0 & 0 \\
0 & 0 & 0 & 1 & 1
\end{array}\right)^{\prime}
$$

Note that parental origins of marker alleles for animal 5 can not be determined.

Then the gametic relationship matrix for the MQTL is obtained as

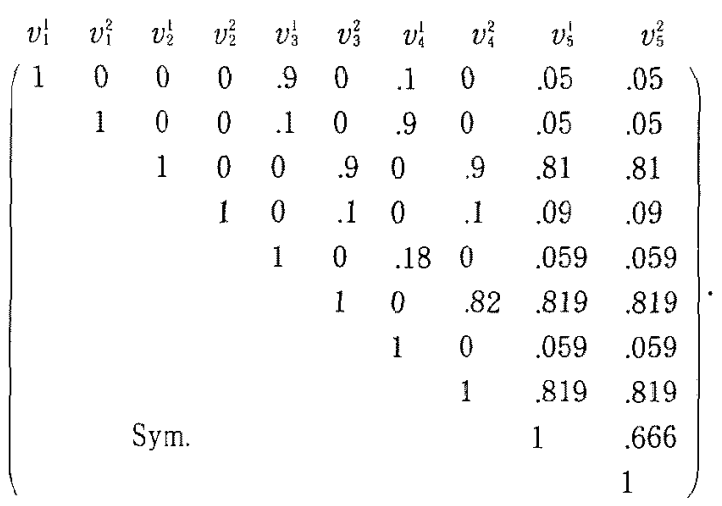

The matrices $Z_{t}$ and $W$ in eq. (9) are given as

$$
\mathbf{Z}_{\mathrm{t}}=\left(\begin{array}{cccc}
1 & 0 & 0 & 0 \\
0 & 1 & 0 & 0 \\
0 & 0 & 1 & 0 \\
0 & 0 & 0 & 1 \\
0 & 0 & .5 & .5
\end{array}\right)
$$

and

Table 1. Example data with pedigree of five animals

\begin{tabular}{ccccc}
\hline \hline Animal & Sire & Dam & Genotype & Observation \\
\hline 1 & - & - & $M_{1} M_{2}$ & 80 \\
2 & - & - & $M_{3} M_{4}$ & 120 \\
3 & 1 & 2 & $M_{1} M_{3}$ & 90 \\
4 & 1 & 2 & $M_{2} M_{3}$ & 110 \\
5 & 3 & 4 & $M_{3} M_{3}$ & 115 \\
\hline
\end{tabular}

$$
\mathbf{W}=\left(\begin{array}{cccccccc}
1 & 1 & 0 & 0 & 0 & 0 & 0 & 0 \\
0 & 0 & 1 & 1 & 0 & 0 & 0 & 0 \\
0 & 0 & 0 & 0 & 1 & 1 & 0 & 0 \\
0 & 0 & 0 & 0 & 0 & 0 & 1 & 1 \\
0 & 0 & 0 & 0 & .1 & .9 & .1 & .9
\end{array}\right)
$$

respectively. The covariance matrix for the residual vector $\phi$ is calculated as

$$
\mathbf{R}=\operatorname{diag}\left(\begin{array}{lllll}
.8 & .8 & .8 & .8 & .968
\end{array}\right),
$$

where $d_{5}=.5$ and $\mathbf{G}_{\mathrm{E} 5}^{*}=\left(\begin{array}{rr}.257 & -.077 \\ -.077 & .257\end{array}\right)$ with

$\mathbf{B}_{5}^{*}=\left(\begin{array}{llll}.05 & .45 & .05 & .45 \\ .05 & .45 & .05 & .45\end{array}\right)$.

Thus, solving the resulting MME given as eq. (10) leads to

$$
\begin{aligned}
& \beta^{\circ}=\left(\begin{array}{ll}
97.0672 & 112.084
\end{array}\right)^{\prime}, \\
& \hat{\mathbf{u}}_{p}=\left(\begin{array}{lll}
-4.97651 & 4.97651-.92367-.17615)^{\prime}
\end{array}\right. \\
& \hat{\mathbf{v}}_{p}=(-.97606-.77672 .76733 .98546-1.02 \\
& .74218-.81568 .78703)^{\prime} \text {. }
\end{aligned}
$$$$
\text { and }
$$

Back-solutions for the non-parent are

$$
\hat{\mathbf{u}}_{o}=(-.19761)^{\prime}
$$

and

$$
\hat{\mathbf{v}}_{a}=\left(\begin{array}{ll}
.61750 & .61750
\end{array}\right)^{\prime} .
$$

These solutions are completely equal to those obtained by the AM approach that accounts for the situation where parental origin of marker alleles can not be determined.

\section{Discussion}

Fernando and Grossman ${ }^{37}$ first presented the methodology for an application of BLUP to MAS in animal breeding. Denoting the numbers of fixed effects, animals in the pedigree file, and MQTLs by $N_{j}, N_{o}$ and $N_{m}$, respectively, the number of equations required in their AM approach becomes $N_{f}+N_{q}\left(2 N_{m}+1\right)$. Hence, the application of the AM approach would be limited to relatively small data sets. Then Cantet and Smith ${ }^{2)}$ developed a RAM version of the AM procedure for MAS, which is one strategy for making the BLUP evaluation computationally efficient. The system of equations required in the RAM approach is of order $N_{f}+N_{q^{*}}\left(2 N_{m}+1\right)$, where $N_{q^{*}}$ is the number of parent animals. Thus, the RAM procedure 
could be especially useful in species where the fraction of non-parents is high and when the number of MQTLs is high.

Fernando and Grossman ${ }^{3)}$ also proposed a recursive algorithm to obtain the covariance matrix for the MQTL effects and presented a simple method to get its inverse, in which information on the parental origins of marker alleles in addition to information on marker genotypes are required. Cantet and Smith's RAM approach ${ }^{2)}$ was described for the situation discussed by Fernando and Grossman ${ }^{3)}$. In the RAM, consequently, the covariance matrix of residual effects for the MQTL, or the segregation residuals, has been defined as diagonal. The parental origin of marker alleles, however, may not be always known. Accordingly, Wang et al. ${ }^{15)}$ extended Fernando and Grossman's work ${ }^{3)}$ to situations where paternal or maternal origin of marker alleles can not be determined and some marker genotypes are uninformative. In this study, the covarince matrix of the segregation residual effects in the RAM for such a situation has been given as block-diagonal, in which the covariance of seg. regation residuals within an animal is defincd appropriately.

Therefore, the RAM approach described herein is an extension of Cantet and Smith's work ${ }^{2)}$. Fortunately, the covariance matrix for the residual effects in the current model remains diagonal. When the algorithm ${ }^{[5)}$ to invert the gametic relationship matrix for the MQTL alleles is used, the calculation of the matrix required is for parents only.

Finally, the BLUP methodology for MAS including the current procedure requires the information of recombination rate between the marker locus and the MQTL and the variance components. However, true values of these parameters are usually unknown. Those values could be estimated, for instance, by the likelihood-based procedures ${ }^{4,14.16)}$, assuming that effects of MQTL alleles follow normality.

\section{References}

1) Botstein D, White RL, Skolnick M, Davis RW. Construction of a genetic linkage map in man using restriction fragment length polymor phisms. Am. J. Hum. Genet., 32 : 314-331. 1980.

2) Cantet RJC, Smith C. Reduced animal model for marker assisted selection using best linear unbiased prediction. Genet. Sel. Evol., 23 : $221-$ 233. 1991.

3) Fernando RL, Grossman M. Marker assisted selection using best linear unbiased prediction. Genet. Sel. Evol., 21: 467-477, 1989.

4) Grignola FE, Hoeschele I, Meyer K. Empirical best linear unbiased prediction to map QTL. In : Proc. 5th World Congr. Genet. Appl. Livest. Prod., 21 : 245-248. 1994.

5) Henderson CR. Sire evaluation and genetic trend. In : Anim. Breed. Genet. Symp. in Honor of Dr. Jay L. Lush, ASAS and ADSA, 10-41. 1973.

6) Jeffreys AJ, Wilson V, Thein SL. Hypervariable "minisatellite" regions in human DNA. Nature, 314:67-73. 1985.

7) Kashi Y, Hallerman E, Soller M. Markerassisted selection of candidate bulls for progeny testing programmes. Anim. Prod., 51 : 6374. 1990.

8) Meuwissen THE, van Arendonk JAM. Potential improvements in rate of genetic gain from marker-assisted selection in dairy cattle breeding schemes. J. Dairy Sci., 75 : 1651-1659. 1992.

9) Nakamura $Y$, Leppert M, O'Connell P, Wolff R, Holm T, Culver M, Martin C, Fujimoto E, Hoff M, Kumlin E, White R. Variable number of tandem repeat (VNTR) markers for human gene mapping. Science, 235 : 1616-1622. 1987.

10) Saito $S$, Iwaisaki $H$. A reduced animal model approach to predicting the total additive genetic merits for marker-assisted selection. Genet. Sel. Evol. (to appear).

11) Saito $S$, Iwaisaki H. A reduced animal model with elimination of quantitative trait loci equations for marker-assisted selection. Genet. Sel. Evol. (to appear).

12) Smith $C$, Simpson SP. The use of genetic polymorphisms in livestock improvement. J. Anim. Breed. Genet., $103:$ 205-217. 1986.

13) Soller M, Beckmann JS. Genetic polymor phism in varietal identification and genetic improvement. Theor. Appl. Genet., $67: 25-33$. 


\title{
SAITO and IWAISAKI
}

1983.

14) van Arendonk JAM, Tier B, Kinghorn BP. Simultaneous estimation of effects of unlinked markers and polygenes on a trait showing quantitative genetic variation. In : Proc. 17 th Int. Congr. Genet., 192. 1993.

15) Wang T, Fernando RI, van der Beek S, Grossman $M$, van Arendonk JAM. Covariance between relatives for a marked quantitative trait locus. Genet. Sel. Evol., 27 : 251-274. 1995.
16) Weller JI, Fernando RL. Strategies for the improvement of animal production using marker -assisted selection. In: Gene Mapping : Strategies, Techniques and Applications (Schook LB, Lewin HA, McLaren DG eds.) 305-328. Marcel Dekker, New York. 1991.

17) Williams JGK, Kubelik AR, Livak KJ, Rafalski JA, Tingey SV. DNA polymorphisms amplified by arbitrary primers are useful as genetic markers. Nucl. Acids Res., 18 : 6531-6535. 1990.

\section{マーカー依存型選抜のための縮約個体モデルにおける 残差効果の共分散構造}

\author{
齋藤聖子・祝前博明* \\ 新潟大学大学院自然科学研究科, 新潟市 950-21 \\ * 新潟大学農学部, 新潟市 950-21
}

マーカー依存型退抜のための縮約個体モデルーBLUP法に関して, 個々の親から子へのマーカー透伝 子の由来が特定できない場合を取り上げて，モデルにおける分離残差効果の共分散構造を示した。あお せて，当該共分散構造を考虚に入れた BLUP 法の方法論を記述し，後代を生産していない個体に関する 解を得るための方程式を与えるとともに，簡単な数值例を示した。

日畜会報, $68(1) ： 1-6,1997$ 